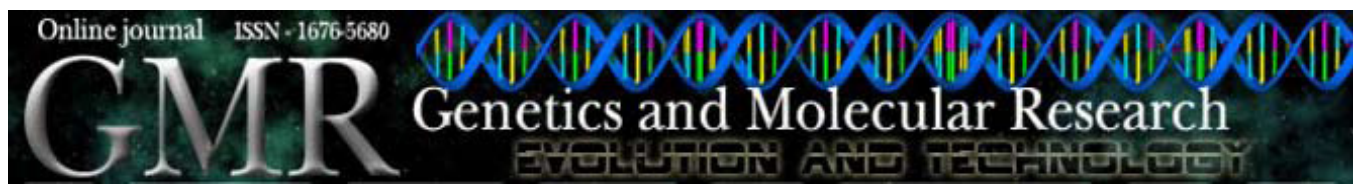

\title{
Genetic characterization of green bean (Phaseolus vulgaris) genotypes from eastern Turkey
}

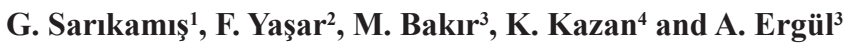 \\ ${ }^{1}$ Department of Horticulture, Faculty of Agriculture, \\ Ankara University, Ankara, Turkey \\ ${ }^{2}$ Department of Horticulture, Faculty of Agriculture, \\ Yüzüncü Yıl University, Van, Turkey \\ ${ }^{3}$ Biotechnology Institute, Ankara University, Ankara, Turkey \\ ${ }^{4}$ Commonwealth Scientific and Industrial Research Organization Plant Industry, \\ Queensland Bioscience Precinct, St. Lucia, Queensland, Australia \\ Corresponding author: A. Ergül \\ E-mail: ergul@agri.ankara.edu.tr; aliergul2001@yahoo.com
}

Genet. Mol. Res. 8 (3): 880-887 (2009)

Received March 25, 2009

Accepted June 2, 2009

Published July 28, 2009

\begin{abstract}
Green bean genotypes collected from eastern Turkey were characterized using simple sequence repeat (SSR) markers and morphological traits. Among 12 SSR markers, 10 produced successful amplifications and revealed DNA polymorphisms that were subsequently used to assess genetic relatedness of the genotypes. Based on the number of alleles generated and the probability of identity values, the most informative SSR loci were PVGLND5, PVMEIG, PVag001, and PV-ag004. Probably, due to the inbreeding nature of beans, the heterozygosity observed within genotypes was low at most of the SSR loci. The UPGMA dendrogram constructed based on the SSR data yielded two major clusters. The overall genetic distance was around $98 \%$, among the genotypes. This information can be used to help select Turkish green bean lines.
\end{abstract}

Key words: Bean; Simple sequence repeat; Genetic resources; Genetic characterization 


\section{INTRODUCTION}

Bean (Phaseolus vulgaris L.) is an important legume grown worldwide for its high nutritional and economic value. In some countries, it is the primary source of protein in the human diet. In addition, bean consumption is increasing based on perceived health benefits associated with certain vitamin and mineral contents. The evaluation of genetic diversity could greatly assist and expedite selection decisions in bean breeding. Therefore, a number of earlier studies have investigated the genetic variation within and between bean populations as well as between cultivated and wild genotypes, using isozymes (Weeden, 1984; Koenig and Gepts, 1989; Belletti and Lotito, 1996), seed protein analysis (Lioi et al., 2005), and molecular markers. For instance, among molecular markers, RFLPs were used to identify patterns of genetic diversity as well as to develop genetic linkage maps in common bean (Vallejos et al., 1992; Gepts et al., 1993; Nodari et al., 1993). Similarly, polymerase chain reaction (PCR)-based DNA markers such as RAPDs and AFLPs were also used extensively to compare the genetic structures of common bean germplasm collections (Skrock and Nienhuis, 1998; Tiwari et al., 2005; Durán et al., 2005), to assess genetic diversity within bean germplasm (Caicedo et al., 1999; Lioi et al., 2005; Sustar-Vozlic et al., 2006; Kumar et al., 2008), and to map resistance genes (Kelly et al., 2003).

More recently, simple sequence repeats (SSRs) have been used by several investigators to determine the genetic diversity within and between bean populations (Métais et al., 2002; Durán et al., 2005; Diaz and Blair, 2006; Blair et al., 2006, 2007; Benchimol et al., 2007; Hanai et al., 2007). A number of polymorphic SSR markers have been developed for beans using DNA sequence information obtained from the GenBank database (Yu et al., 2000; Blair et al., 2003) as well as sequencing of anonymous bean clones from genomic libraries (Gaitán-Solís et al., 2002; Métais et al., 2002).

With an annual production of 499,298 tons, Turkey is an important green bean producer in the world (FAO, 2007). Green bean production in Turkey is mainly in the Black Sea region. Previous genetic studies partially characterized the green bean genotypes collected from the Black Sea region (Balkaya, 1999; Balkaya and Yanmaz, 2002). The Gevaş and Erciş districts of Van province from the eastern part of Turkey are also important green bean production areas in the country. However, the green bean genotypes from this region have not been previously characterized genetically. Climatically, eastern Turkey differs greatly from the Black Sea region. Therefore, it is expected that the green bean germplasm from this region would have economically important adaptive traits that can potentially be incorporated into bean breeding programs. In an attempt to evaluate the green bean genetic resources of eastern Turkey, several green bean genotypes have been collected from this region. The aim of the present study was to assess the level of genetic diversity present in the genotypes from this region. It is hoped that the information presented here will aid selection and more efficient utilization of this germplasm in bean breeding programs.

\section{MATERIAL AND METHODS}

\section{Plant material}

The green bean genotypes used in this study were collected from the Erciş and Gevaş districts of Van province, in the eastern part of Turkey. A total of 28 green bean genotypes to- 
gether with two reference cultivars, Gina (Asgrow Seed) and Sazova, 1949 (Eskişehir), were used for morphological and SSR analysis. The locations and some of the morphological traits such as growth habit, pod and terminal leaflet characteristics of these genotypes grown and scored according to the guidelines for conducting tests for distinctness, homogeneity and stability criteria for new varieties of plants provided by the International Union for the Protection of New Varieties of Plants (UPOV) are presented as an average of two years in Table 1.

\begin{tabular}{|c|c|c|c|c|c|c|c|c|c|}
\hline \multirow{2}{*}{$\begin{array}{l}\text { Accession } \\
\text { number }\end{array}$} & \multirow[t]{2}{*}{ Location } & \multirow[t]{2}{*}{ Growth habit } & \multicolumn{4}{|c|}{ Pod } & \multicolumn{3}{|c|}{ Terminal leaflet } \\
\hline & & & Ground color & $\begin{array}{l}\text { Density } \\
\text { of flecks }\end{array}$ & $\begin{array}{c}\text { Degree } \\
\text { of curvature }\end{array}$ & $\begin{array}{c}\text { Texture } \\
\text { of surface }\end{array}$ & Stringiness & Size & Shape \\
\hline 2 & Erciş & climbing & dark green & sparse & medium & smooth & absent & medium & triangular \\
\hline 16 & Erciş & climbing & light green & sparse & medium & smooth & absent & medium & triangular to circular \\
\hline 17 & Erciş & climbing & light green & sparse & weak & smooth & absent & medium & triangular to circular \\
\hline 23 & Gevaş & climbing & dark green & sparse & medium & smooth & absent & medium & triangular to circular \\
\hline 24 & Gevaş & climbing & dark green & sparse & weak & smooth & absent & medium & triangular to circular \\
\hline 25 & Gevaş & climbing & light green & sparse & weak & smooth & absent & medium & triangular to circular \\
\hline 28 & Gevaş & climbing & light green & sparse & weak & smooth & absent & medium & rhombic \\
\hline 32 & Gevaş & climbing & green & sparse & weak & smooth & absent & medium & triangular to circular \\
\hline 36 & Gevaş & climbing & light green & sparse & medium & smooth & present & large & triangular \\
\hline 37 & Gevaş & climbing & light green & sparse & weak & smooth & present & medium & triangular to circular \\
\hline 38 & Gevaş & climbing & light green & sparse & weak & smooth & absent & medium & triangular \\
\hline 40 & Gevaş & climbing & light green & sparse & weak & smooth & absent & small & triangular \\
\hline 45 & Gevaş & climbing & light green & sparse & weak & smooth & absent & medium & triangular \\
\hline 47 & Gevaş & climbing & light green & sparse & medium & smooth & absent & medium & triangular \\
\hline 52 & Gevaş & climbing & light green & sparse & medium & smooth & present & medium & triangular \\
\hline 53 & Gevaş & climbing & light green & sparse & medium & smooth & present & medium & triangular \\
\hline 57 & Gevaş & climbing & green & sparse & weak & smooth & absent & medium & triangular \\
\hline 64 & Gevaş & dwarf & light green & sparse & weak & smooth & absent & medium & triangular \\
\hline 65 & Gevaş & dwarf & light green & sparse & weak & smooth & present & medium & triangular \\
\hline 69 & Gevaş & dwarf & dark green & medium & weak & smooth & present & medium & triangular \\
\hline 70 & Gevaş & dwarf & dark green & sparse & medium & smooth & present & medium & triangular \\
\hline 73 & Gevaş & dwarf & light green & sparse & weak & smooth & present & medium & triangular \\
\hline 74 & Gevaş & dwarf & dark green & sparse & medium & smooth & absent & medium & triangular \\
\hline 77 & Gevaş & dwarf & light green & sparse & medium & smooth & absent & medium & triangular \\
\hline 79 & Gevaş & dwarf & light green & sparse & weak & smooth & absent & medium & triangular \\
\hline 80 & Gevaş & dwarf & dark green & sparse & weak & smooth & present & medium & triangular \\
\hline 84 & Gevaş & climbing & light green & sparse & weak & smooth & absent & medium & triangular \\
\hline 87 & Gevaş & climbing & dark green & dense & medium & smooth & absent & large & triangular \\
\hline S.1949 & Eskişehir & climbing & green & sparse & medium & smooth & absent & medium & triangular \\
\hline Gina & Asgrow & dwarf & green & sparse & weak & smooth & absent & medium & triangular to circular \\
\hline
\end{tabular}

S.1949: Sazova 1949.

\section{DNA extraction}

Genomic DNA was extracted from young leaf tissue using the Wizard ${ }^{\circledR}$ Genomic DNA Purification Kit (Promega, Madison, WI) according to instructions provided by the manufacturer. Subsequently an RNAse treatment was performed on the eluted DNA samples. Purity and concentration of the DNA were both checked on $1 \%(\mathrm{w} / \mathrm{v})$ agarose gels and NanoDrop ${ }^{\circledR}$ ND-1000 Spectrophotometer. 


\section{SSR analysis}

Twelve SSR primer pairs were initially selected from a list of bean SSR primers given by Yu et al. (2000) based on their reliable amplification patterns and high polymorphic information contents. The sequence information of the SSR loci, PVU70530 and PVMEIG, was obtained from Lioi et al. (2005). PCR was conducted in a volume of $10 \mu \mathrm{L}$ and contained $15 \mathrm{ng}$ genomic DNA, 5 pmol of each primer, $0.5 \mathrm{mM}$ dNTP, 0.5 unit GoTaq DNA polymerase (Promega), $1.5 \mathrm{mM} \mathrm{MgCl}$ and $2 \mu \mathrm{L} 5 \mathrm{X}$ buffer. The forward primers were labeled with WellRED fluorescent dyes D2 (black), D3 (green) and D4 (blue) (Proligo, Paris, France). Reactions without DNA were included as negative controls. PCR amplification was performed using the Biometra ${ }^{\circledR}$ PCR System. The amplification conditions consisted of an initial denaturation step of $3 \mathrm{~min}$ at $94^{\circ} \mathrm{C}$, followed by 35 cycles of $1 \mathrm{~min}$ at $94^{\circ} \mathrm{C}, 1 \mathrm{~min}$ at $52-56^{\circ} \mathrm{C}$ and $2 \mathrm{~min}$ at $72^{\circ} \mathrm{C}$ with a final extension at $72^{\circ} \mathrm{C}$ for 10 min. The PCR products were first separated on a $3 \%(\mathrm{w} / \mathrm{v})$ agarose gel run at $80 \mathrm{~V}$ for $2 \mathrm{~h}$. The gel was then stained with ethidium bromide at a concentration of $10 \mathrm{mg} / \mathrm{mL}$. A DNA ladder (100 bp) (Promega) was used for the approximate quantification of the bands. The amplification products were visualized under UV light, and their sizes were estimated relative to the DNA ladder. For further determination of polymorphisms, the PCR products were run on CEQ ${ }^{\mathrm{TM}} 8800 \mathrm{XL}$ capillary Genetic Analysis System (Beckman Coulter, Fullerton, CA). The analyses were repeated at least twice to ensure reproducibility of the results. Allele sizes were determined for each SSR locus using the Beckman CEQ ${ }^{\mathrm{TM}}$ fragment analysis software. In each run, Gina and Sazova (1949) cultivars were included as reference cultivars.

\section{Genetic analysis}

The genetic analysis program "IDENTITY" 1.0 (Wagner and Sefc, 1999) was used according to Paetkau et al. (1995) for the calculation of number of alleles, allele frequency, expected and observed heterozygosity, estimated frequency of null alleles, and probability of identity per locus. Genetic dissimilarity was determined by the program "MICROSAT" (version 1.5) (Minch et al., 1995) using proportion of shared alleles, which was calculated by using "ps (option 1 - (ps))", as described by Bowcock et al. (1994). The results were then converted to a similarity matrix, and a dendrogram was constructed with the unweighted pair-group method with arithmetic mean (UPGMA) method (Sneath and Sokal, 1973) using the software NTSYS-pc (Numerical Taxonomy and Multiware Analysis System,version 2.0) (Rohlf, 1988).

\section{RESULTS}

The level of genetic diversity among 28 green bean genotypes collected from the eastern part of Turkey (along with two reference cultivars) were assessed using 10 SSR markers. As a result, a total of 45 alleles were detected with an average allele number of 4.5 (Table 2). The PV-at006, PV-ctt001 and PV-ag003 loci generated the lowest number of alleles ( 2 alleles) whereas the PVGLND5 locus generated the highest number of alleles (10 alleles) (Table 3$)$. 


\begin{tabular}{|c|c|c|c|c|c|c|c|c|c|c|c|c|c|c|c|c|c|c|c|c|}
\hline \multicolumn{11}{|c|}{$\begin{array}{l}\text { Accession } \\
\text { number }\end{array}$} & \multicolumn{10}{|l|}{ Loci } \\
\hline \multirow[b]{2}{*}{2} & \multicolumn{2}{|c|}{ PV-at002 } & \multicolumn{2}{|c|}{ PV-ag001 } & \multicolumn{2}{|c|}{ PV-ag004 } & \multicolumn{2}{|c|}{ PV-ggc001 } & \multicolumn{2}{|c|}{ PV-at006 } & \multicolumn{2}{|c|}{ PVMEIG } & \multicolumn{2}{|c|}{ PV-ctt001 } & \multicolumn{2}{|c|}{ PVU70530 } & \multicolumn{2}{|c|}{ PVGLND5 } & \multicolumn{2}{|c|}{ PV-ag003 } \\
\hline & 249 & 249 & 155 & 155 & 203 & 239 & 230 & 230 & 128 & 128 & 192 & 192 & 161 & 161 & 243 & 243 & 108 & 202 & 163 & 163 \\
\hline 16 & 247 & 247 & 157 & 157 & 203 & 239 & 230 & 230 & 128 & 128 & 198 & 198 & 161 & 161 & 243 & 243 & 108 & 162 & 163 & 163 \\
\hline 17 & 249 & 249 & 157 & 157 & 203 & 239 & 230 & 230 & 128 & 128 & 198 & 198 & 161 & 161 & 243 & 243 & 150 & 150 & 163 & 163 \\
\hline 23 & 245 & 245 & 151 & 151 & 203 & 239 & 230 & 230 & 128 & 128 & 204 & 220 & 161 & 161 & 243 & 243 & 108 & 172 & 163 & 163 \\
\hline 24 & 245 & 245 & 151 & 151 & 203 & 239 & 230 & 230 & 128 & 128 & 216 & 216 & 161 & 161 & 243 & 243 & 108 & 172 & 163 & 163 \\
\hline 25 & 245 & 245 & 155 & 155 & 203 & 239 & 230 & 230 & 128 & 128 & 220 & 220 & 161 & 161 & 243 & 243 & 108 & 186 & 163 & 163 \\
\hline 28 & 245 & 245 & 151 & 151 & 203 & 239 & 230 & 230 & 128 & 128 & 224 & 224 & 161 & 161 & 243 & 243 & 108 & 174 & 163 & 163 \\
\hline 32 & 245 & 245 & 153 & 153 & 203 & 239 & 230 & 230 & 128 & 128 & 192 & 192 & 155 & 155 & 243 & 243 & 174 & 174 & 163 & 163 \\
\hline 36 & 245 & 245 & 157 & 157 & 203 & 239 & 230 & 230 & 128 & 128 & 224 & 224 & 161 & 161 & 243 & 243 & 108 & 180 & 163 & 163 \\
\hline 37 & 245 & 245 & 151 & 151 & 203 & 239 & 230 & 230 & 128 & 128 & 220 & 220 & 161 & 161 & 243 & 243 & 108 & 108 & 163 & 163 \\
\hline 38 & 245 & 245 & 157 & 157 & 203 & 239 & 230 & 230 & 128 & 128 & 224 & 224 & 161 & 161 & 245 & 245 & 108 & 186 & 161 & 161 \\
\hline 40 & 245 & 245 & 155 & 155 & 203 & 239 & 230 & 230 & 128 & 128 & 204 & 224 & 161 & 161 & 243 & 243 & 108 & 180 & 163 & 163 \\
\hline 45 & 245 & 245 & 157 & 157 & 203 & 239 & 230 & 230 & 128 & 128 & 220 & 220 & 161 & 161 & 243 & 43 & 108 & 182 & 63 & 163 \\
\hline 47 & 245 & 245 & 157 & 157 & 203 & 239 & 230 & 230 & 128 & 128 & 222 & 222 & 161 & 161 & 243 & 243 & 108 & 180 & 163 & 163 \\
\hline 52 & 245 & 245 & 157 & 157 & 203 & 239 & 230 & 230 & 128 & 128 & 216 & 216 & 161 & 161 & 243 & 243 & 108 & 80 & 163 & 163 \\
\hline 53 & 245 & 245 & 143 & 143 & 203 & 239 & 230 & 230 & 128 & 128 & 224 & 224 & 161 & 161 & 243 & 243 & 108 & 182 & 163 & 163 \\
\hline 57 & 245 & 245 & 157 & 157 & 203 & 239 & 230 & 230 & 128 & 128 & 224 & 224 & 161 & 161 & 243 & 243 & 150 & 150 & 163 & 163 \\
\hline 64 & 247 & 247 & 147 & 147 & 203 & 239 & 230 & 230 & 128 & 128 & 210 & 210 & 161 & 161 & 243 & 243 & 150 & 164 & 163 & 163 \\
\hline 65 & 245 & 245 & 157 & 157 & 203 & 239 & 230 & 230 & 128 & 128 & 220 & 220 & 161 & 161 & 243 & 243 & 108 & 180 & 163 & 163 \\
\hline 69 & 245 & 245 & 155 & 155 & 203 & 239 & 230 & 230 & 128 & 128 & 224 & 224 & 161 & 161 & 243 & 243 & 108 & 164 & 163 & 163 \\
\hline 70 & 245 & 245 & 155 & 155 & 203 & 239 & 230 & 230 & 128 & 128 & 204 & 204 & 161 & 161 & 243 & 243 & 150 & 150 & 163 & 163 \\
\hline 73 & 245 & 245 & 157 & 157 & 201 & 239 & 230 & 230 & 128 & 128 & 224 & 224 & 161 & 161 & 243 & 243 & 108 & 182 & 163 & 163 \\
\hline 74 & 245 & 245 & 157 & 157 & 203 & 239 & 230 & 230 & 128 & 128 & 224 & 224 & 161 & 161 & 243 & 243 & 108 & 182 & 163 & 163 \\
\hline 77 & 245 & 245 & 157 & 157 & 203 & 239 & 230 & 230 & 128 & 128 & 220 & 220 & 161 & 161 & 243 & 243 & 108 & 182 & 163 & 163 \\
\hline 79 & 245 & 245 & 157 & 157 & 203 & 239 & 230 & 230 & 128 & 128 & 224 & 192 & 161 & 161 & 243 & 243 & 108 & 182 & 163 & 163 \\
\hline 80 & 245 & 245 & 157 & 157 & 201 & 239 & 230 & 241 & 128 & 128 & 224 & 224 & 161 & 161 & 243 & 243 & 108 & 182 & 163 & 163 \\
\hline 84 & 245 & 245 & 155 & 155 & 203 & 239 & 230 & 230 & 128 & 128 & 216 & 216 & 161 & 161 & 243 & 243 & 150 & 150 & 163 & 163 \\
\hline 87 & 245 & 245 & 151 & 151 & 203 & 239 & 230 & 230 & 128 & 128 & 192 & 192 & 161 & 161 & 243 & 243 & 164 & 164 & 163 & 163 \\
\hline S.1949 & 245 & 245 & 149 & 149 & 201 & 239 & 230 & 230 & 128 & 128 & 198 & 198 & 161 & 161 & 243 & 243 & 108 & 164 & 163 & 163 \\
\hline Gina & 245 & 245 & 147 & 147 & 203 & 239 & 235 & 235 & 128 & 128 & 192 & 192 & 161 & 161 & 241 & 241 & 150 & 150 & 163 & 163 \\
\hline
\end{tabular}

S.1949: Sazova, 1949.

Table 3. Number of alleles, allele range (bp), expected heterozygosity, observed heterozygosity, and probability of identity values of green bean genotypes calculated at 10 simple sequence repeat loci.

\begin{tabular}{|c|c|c|c|c|c|c|}
\hline Loci analyzed & $\begin{array}{c}\text { Allele } \\
\text { range (bp) }\end{array}$ & $\begin{array}{l}\text { Number } \\
\text { of alleles }\end{array}$ & $\begin{array}{c}\text { Expected } \\
\text { heterozygosity }\end{array}$ & $\begin{array}{c}\text { Observed } \\
\text { heterozygosity }\end{array}$ & $\begin{array}{c}\text { Estimated frequency } \\
\text { of null alleles }\end{array}$ & $\begin{array}{l}\text { Probability } \\
\text { of identity }\end{array}$ \\
\hline PV-ag001 & $143-157$ & 7 & 0.695 & 0 & 0.410 & 0.201 \\
\hline PV-ggc001 & $230-241$ & 3 & 0.150 & 0.032 & 0.102 & 0.744 \\
\hline PV-at002 & $245-249$ & 3 & 0.233 & 0 & 0.189 & 0.626 \\
\hline PV-ag004 & $201-241$ & 5 & 0.573 & 1 & -0.271 & 0.455 \\
\hline PV-at006 & $128-170$ & 2 & 0.062 & 0 & 0.058 & 0.884 \\
\hline PVMEIG & $192-224$ & 8 & 0.805 & 0.096 & 0.392 & 0.110 \\
\hline PVGLND5 & $108-202$ & 10 & 0.787 & 0.709 & 0.043 & 0.116 \\
\hline PV-ctt001 & $155-161$ & 2 & 0.120 & 0 & 0.107 & 0.795 \\
\hline PV-ag003 & $161-163$ & 2 & 0.06 & 0 & 0.058 & 0.884 \\
\hline PVU70530 & $241-245$ & 3 & 0.122 & 0 & 0.109 & 0.780 \\
\hline
\end{tabular}


The UPGMA dendrogram obtained using the SSR data generated two major clusters. A single genotype (genotype 37) clustered separately from the remaining 27 genotypes and the two reference cultivars forming a separate branch (Figure 1). The two reference cultivars together with seven genotypes, three of which were from the Erciş district clustered together within the second cluster. The remaining genotypes, all from the Gevaş district, clustered as a single branch within the second cluster.

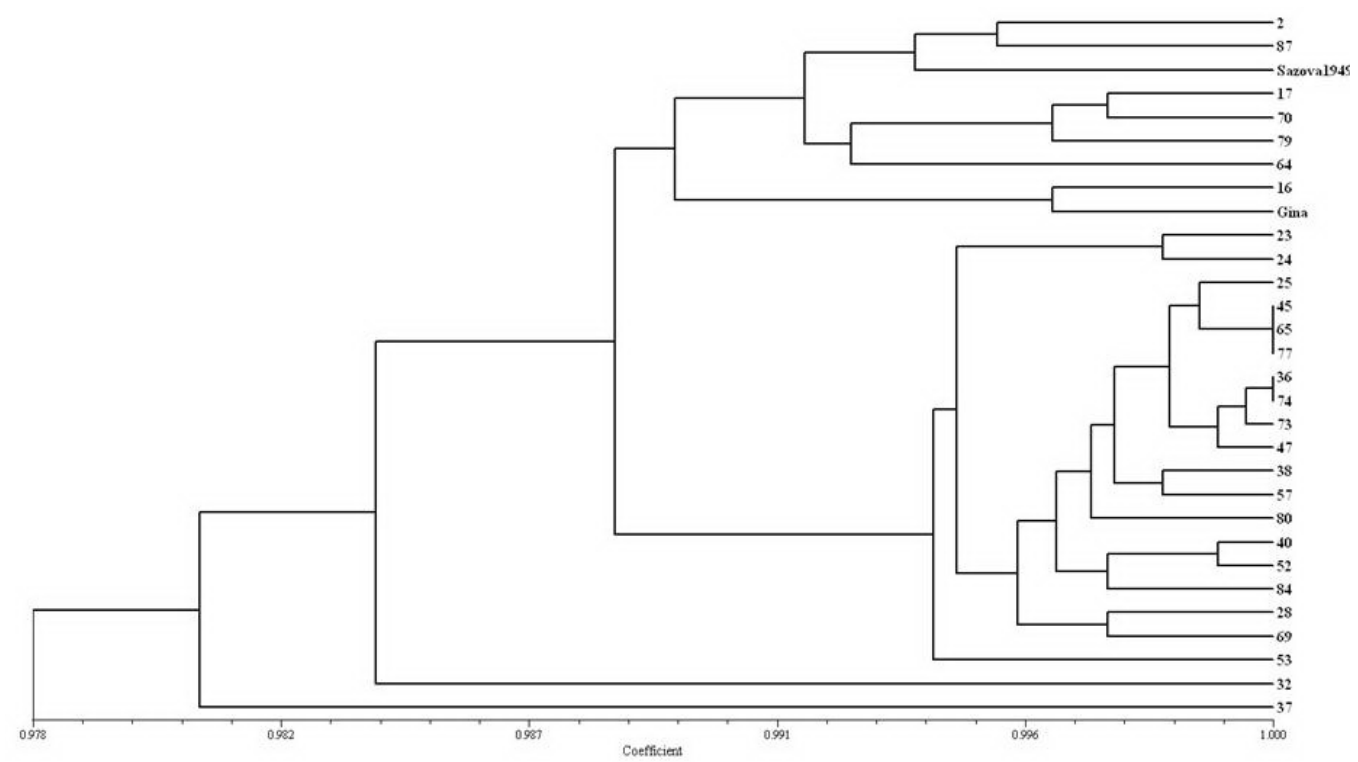

Figure 1. Dendrogram showing the relationships of 28 green bean genotypes together with two cultivars (Gina and Sazova, 1949) based on UPGMA cluster analysis of 10 simple sequence repeat marker data.

Among the green bean genotypes analyzed in the present study, two cases of identity were found $(77,45$ and $65 ; 36$ and 74$)$. When the genetic similarity of the genotypes was analyzed, the similarity ratio of all genotypes analyzed was not below $98 \%$ (Figure 1, Table 2).

\section{DISCUSSION}

The present study, using molecular markers and morphological traits, investigated the genetic relationships of green bean genotypes from a bean growing region of Turkey. Although green bean lines originating from the Black Sea region were previously characterized (Balkaya, 1999; Balkaya and Yanmaz, 2002), the green bean genotypes from eastern Turkey had not been genetically characterized before. Therefore, these are important first steps towards better understanding and maintenance of green bean germplasm of the region.

SSR markers, widely spread throughout the nuclear genomes of eukaryotes, known to reveal high levels of polymorphisms, were used in the present study. Taken together with their 
codominant nature and reproducibility, SSR markers are very useful for the analysis of genetic diversity, genomic mapping and marker-assisted selection in many plant species compared to many other marker systems. In the present study, ten of twelve SSR markers selected from the GenBank database produced successful amplification of expected sizes. For most samples tested, two of the markers, PVSBE2 and PV18791, did not produce any amplification products. Of these two primers, PVSBE2 was previously reported to reveal null alleles (Lioi et al., 2005). The SSR data generated in this study can be potentially incorporated into future studies that examine the diversity within a larger collection of bean genotypes from diverse regions.

The average number of alleles revealed in the present study is consistent with data reported in similar studies (Métais et al., 2002). Based on the number of alleles generated and probability of identity values, the most informative loci were PVGLND5, PVMEIG, PVag001, and PV-ag004 (Table 3). The remaining five loci, PV-at002, PV-ggc001, PV-at006, PVctt001, and PV-ag003, revealed a low number of alleles and high probability of identity values. Similar to our findings, PVGLND5 and PVMEIG were reported to reveal high levels of polymorphisms in some Italian common bean landraces (Métais et al., 2002; Lioi et al., 2005). Also, similar to the findings of Diaz and Blair (2006), the observed heterozygosity within each accession was low in this study for all genotypes examined, which is most likely due to the inbreeding nature of common bean. However, the observed heterozygosity was higher at the PV-ag004 locus probably due to the heterozygous state of the genotypes at this specific locus, revealed and confirmed by both gel image pictures and fragment analyzer, implying that the genotypes were not pure inbreds carrying two different alleles at this particular locus.

The close genetic distance even between the most distantly related genotypes (97.8\%) indicates a very close genetic relationship among the genotypes. This low level of polymorphism observed among the genotypes could be due to the relatively close proximity of the collection sites and probably to the breeders' intense selection.

Our findings also indicated that genotypes 77, 45 and 65, and genotypes 36 and 74 were identical. However, these otherwise molecularly identical genotypes displayed some morphological differences.

Considering the environmental conditions of the region, it is expected that the green bean germplasm from the region would have economically important adaptive traits that can potentially be incorporated into bean breeding programs. Hence, it is expected that the results of this study will assist current bean breeding efforts in Turkey as well as maintain the genetic integrity of the genetic resources.

\section{REFERENCES}

Balkaya A (1999). A Research on Collection of Genetic Resources, Determination of Phenological and Morphological Characteristics and Selection of Suitable Types for Fresh Consumption by Pedigree Selection in Green Bean (Phaseolus vulgaris L.) in the Black Sea Region. Doctoral thesis, Samsun Ondokuz Mayis University, Samsun, Turkey.

Balkaya A and Yanmaz R (2002). Morphological properties of cultivar nominates selected Black Sea Region bean populations and identification by protein markers. Ankara Univ. J. Agric. Sci. 9: 182-188.

Belletti P and Lotito S (1996). Identification of runner bean genotypes, Phaseolus coccineus L., by means of isozyme analysis. J. Genet. Breed. 50: 185-190.

Benchimol LL, Campos T, Carbonell SAM, Colombo CA, et al. (2007). Structure of genetic diversity among common bean (Phaseolus vulgaris L.) varieties of Mesoamerican and Andean origins using new developed microsatellite markers. Genet. Res. Crop Evol. 54: 1747-1762.

Blair MW, Pedraza F, Buendia HF, Gaitan-Solis E, et al. (2003). Development of a genome-wide anchored microsatellite 
map for common bean (Phaseolus vulgaris L.). Theor. Appl. Genet. 107: 1362-1374.

Blair MW, Giraldo MC, Buendia HF, Tovar E, et al. (2006). Microsatellite marker diversity in common bean (Phaseolus vulgaris L.). Theor. Appl. Genet. 113: 100-109.

Blair MW, Diaz JM, Hidalgo R, Diaz LM, et al. (2007). Microsatellite characterization of Andean races of common bean (Phaseolus vulgaris L.). Theor. Appl. Genet. 116: 29-43.

Bowcock AM, Ruiz-Linares A, Tomfohrde J, Minch E, et al. (1994). High resolution of human evolutionary trees with polymorphic microsatellites. Nature 368: 455-457.

Caicedo AL, Gaitán E, Duque MC, Toro Chica O, et al. (1999). AFLP fingerprinting of Phaseolus lunatus L. and related wild species from South America. Crop Sci. 39: 1497-1507.

Diaz LM and Blair MW (2006). Race structure within the Mesoamerican gene pool of common bean (Phaseolus vulgaris L.) as determined by microsatellite markers. Theor. Appl. Genet. 114: 143-154.

Durán LA, Blair MW, Giraldo MC, Macchiavelli R, et al. (2005). Morphological and molecular characterization of common bean landraces and cultivars from the Caribbean. Crop Sci. 45: 1320-1328.

Food and Agriculture Organization of the United Nations (FAO) (2007). FAOSTAT. Available at [http://faostat.fao.org], [http://faostat.fao.org/site/567/DesktopDefault.aspx?PageID=567\#ancor].

Gaitán-Solís E, Duque MC, Edwards KJ and Tohme J (2002). Microsatellite repeats in common bean (Phaseolus vulgaris): Isolation, characterization, and cross-species amplification in Phaseolus ssp. Crop Sci. 42: 2128-2136.

Gepts P, Nodari R, Tsai R, Koinange EMK, et al. (1993). Linkage mapping in common bean. Ann. Rep. Bean Improv. Coop. 36: 24-38.

Hanai LR, de Campos T, Camargo LE, Benchimol LL, et al. (2007). Development, characterization, and comparative analysis of polymorphism at common bean SSR loci isolated from genic and genomic sources. Genome 50: 266-277.

Kelly JD, Gepts P, Miklas PN and Coyne DP (2003). Tagging and mapping of genes and QTL and molecular markerassisted selection for traits of economic importance in bean and cowpea. Field Crops Res. 82: 135-154.

Koenig R and Gepts P (1989). Allozyme diversity in wild Phaseolus vulgaris: further evidence for two major centers of genetic diversity. Theor. Appl. Genet. 78: 809-817.

Kumar V, Sharma S, Kero S, Sharma S, et al. (2008). Assessment of genetic diversity in common bean (Phaseolus vulgaris L.) germplasm using amplified fragment length polymorphism (AFLP). Sci. Hortic. 116: 138-143.

Lioi L, Piergiovanni AR, Pignone D, Puglisi S, et al. (2005). Genetic diversity of some surviving on-farm Italian common bean (Phaseolus vulgaris L.) landraces. Plant Breed. 124: 576-581.

Métais I, Hamon B, Jalouzot R and Peltier D (2002). Structure and level of genetic diversity in various bean types evidenced with microsatellite markers isolated from a genomic enriched library. Theor. Appl. Genet. 104: 1346-1352.

Minch E, Ruiz-Linares A, Goldstein DB, Feldman M, et al. (1995). Microsat (Version 1.4d): a Computer Program for Calculating Various Statistics on Microsatellite Allele Data. Stanford University Medical Center, Stanford.

Nodari RO, Tsail SM, Gilbertson RL and Gepts P (1993). Towards an integrated linkage map of common bean 2. Development of an RFLP-based linkage map. Theor. Appl. Genet. 85: 513-520.

Paetkau D, Calvert W, Stirling I and Strobeck C (1995). Microsatellite analysis of population structure in Canadian polar bears. Mol. Ecol. 4: 347-354.

Rohlf FJ (1988). NTSYS-PC Numerical Taxonomy and Multivariate Analysis System. Exeter Publishing, New York.

Skroch PW and Nienhuis J (1998). Comparison of Mexican common bean (Phaseolus vulgaris L.) core and reserve germplasm collections. Crop Sci. 38: 488-496.

Sneath PH and Sokal RR (1973). Numerical Taxonomy. Freeman, San Francisco.

Sustar-Vozlic J, Maras M, Javornic B and Meglic V (2006). Genetic diversity and origin of Slovene common bean (Phaseolus vulgaris L.) germplasm as revealed by AFLP markers and phaseolin analysis. J. Am. Soc. Hort. Sci. 131: 242-249.

Tiwari M, Singh NK, Rathore M and Kumar N (2005). RAPD markers in the analysis of genetic diversity among common bean germplasm from Central Himalaya. Genet. Res. Crop Evol. 52: 315-324.

Vallejos CE, Sakiyama NS and Chase CE (1992). A molecular marker-based linkage map of Phaseolus vulgaris L. Genetics 131: 733-740.

Wagner HW and Sefc KM (1999). Identity1.0. Centre for Applied Genetics. University of Agricultural Science, Vienna.

Weeden NF (1984). Distinguishing among white seeded bean cultivars by means of allozyme genotypes. Euphytica 33: 199-208.

Yu K, Park SJ, Poysa V and Gepts P (2000). Integration of simple sequence repeat (SSR) markers into a molecular linkage map of common bean (Phaseolus vulgaris L.). J. Hered. 91: 429-434. 